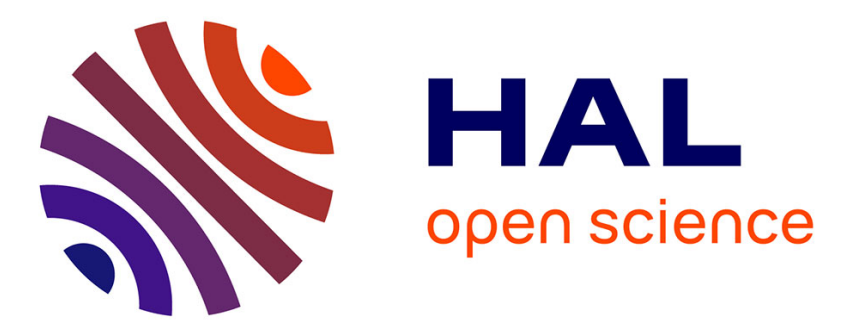

\title{
Thermophysical properties and heat transfer performance of carbon nanotubes water-based nanofluids
}

\author{
Patrice Estellé, Salma Halelfadl, Thierry Maré
}

\section{To cite this version:}

Patrice Estellé, Salma Halelfadl, Thierry Maré. Thermophysical properties and heat transfer performance of carbon nanotubes water-based nanofluids. Journal of Thermal Analysis and Calorimetry, 2017, 127 (3), pp.2075-2081. 10.1007/s10973-016-5833-8 . hal-01368812

\section{HAL Id: hal-01368812 \\ https://hal.science/hal-01368812}

Submitted on 20 Sep 2016

HAL is a multi-disciplinary open access archive for the deposit and dissemination of scientific research documents, whether they are published or not. The documents may come from teaching and research institutions in France or abroad, or from public or private research centers.
L'archive ouverte pluridisciplinaire HAL, est destinée au dépôt et à la diffusion de documents scientifiques de niveau recherche, publiés ou non, émanant des établissements d'enseignement et de recherche français ou étrangers, des laboratoires publics ou privés. 
THERMOPHYSICAL PROPERTIES AND HEAT TRANSFER PERFORMANCE OF CARBON NANOTUBES WATER-BASED NANOFLUIDS

\author{
Patrice Estelle ${ }^{1, *}$, Salma Halelfadl ${ }^{2}$, Thierry Maré ${ }^{3}$ \\ ${ }^{1}$ LGCGM, Matériaux et Thermo-Rhéologie, Université Rennes 1, Rennes, France \\ ${ }^{2}$ Cellule Recherche et développement, Polymont Engineering, France \\ ${ }^{3}$ LGCGM, Matériaux et Thermo-Rhéologie, Université Rennes 1, Saint-Malo, France
}

*Author for correspondence : patrice.estelle@univ-rennes1.fr 


\begin{abstract}
In this paper, thermal conductivity and rheological properties of CNT water-based nanofluids were experimentally measuredwhereas density and heat capacity were evaluated from appropriate theoretical correlations. The influence of nanoparticle content and base fluids on thermophysical properties of nanofluids were presented and discussed. Then, the thermal performance and convective heat transfer of such nanofluids were investigated in a coaxial heat exchanger working in co-current flow. Fixed wall temperature boundary condition and laminar regime were also considered during the experiments. The results were presented discussing the effect of the entrance region, Reynolds number and nanofluids composition.
\end{abstract}

Keywords: CNT nanofluids; Thermophysical properties; Convective heat transfer

\title{
Nomenclature
}

$\begin{array}{lll}\phi & \% & \text { Concentration } \\ \lambda & \mathrm{W} \mathrm{m}^{-1} \mathrm{~K}^{-1} & \text { Thermal conductivity } \\ h & \mathrm{~W} \mathrm{~m}^{-2} \mathrm{~K} & \text { Convective heat coefficient } \\ C_{p} & \mathrm{Jkg}^{-1} \mathrm{~K}^{-1} & \text { Specific heat } \\ \rho & \mathrm{kg} \mathrm{m}^{-3} & \text { Density } \\ N u & & \text { Nusselt number } \\ R e & & \text { Reynolds number } \\ T & { }^{\circ} \mathrm{C} & \text { Temperature } \\ x & \mathrm{~m} & \text { Axial distance } \\ e & \mathrm{~m} & \text { Thickness } \\ D & \mathrm{~m} & \text { Inner diameter of the tube } \\ m & \mathrm{~kg} \mathrm{~s}^{-1} & \text { Mass flow rate }\end{array}$

Special characters

W

EG

N2

N6

wt

Subscripts

bf

np

$n f$

th

$a$

$s$
Water

Ethylene-Glycol

Nanofluids with water as base

fluid

Nanofluids with EG+water as

base fluid

Weight fraction

Base fluid

Nanoparticle

Nanofluid

Thermocouple

Annular tube

Stainless steel

\section{Introduction}


Most of the scientific community agrees that pollution and global climate change, due mainly to excessive carbon dioxide emissions, threaten the environment. As industry is one of the highest energy-using sectors, a shift towards improved energy efficiency in industry, especially in thermal systems, is a new challenge to reduce energy consumption and gas emission [1].

Over the past decade, many methods have been implemented for heat transfer enhancement. This enhancement can be achieved by decreasing thermal boundary layer thickness, increasing velocity gradient near heat-transfer wall, disrupting fluid flow, increasing velocity from laminar flow to turbulent flow, increasing extending surface of heated wall and changing thermophysical properties of surface and fluids [2-4]. Heat transfer properties of conventional working fluids is a primary obstacle in making efficient and compact thermal systems especially in heat exchanger which are widely used in industries.

It is now well established that nanofluids are challenging materials with promising use in heat exchangers, energy and convective systems, solar collectors, electronic devices... They also appear as a worldwide research topic due to their potential applications. Nanofluids exhibit higher thermal conductivity than base fluids which is significantly increased with increasing concentration of nanoparticles. The nature of nanoparticle also plays a role in these benefits over conventional fluids. Also, carbon-based nanomaterials are of main interest because of their excellent intrinsic thermal properties.

Ding et al. [5] have studied the effect of axial distance on heat transfer of multi-walled carbon nanotubes flowing through a horizontal tube. Their results have shown that the enhancement is a function of axial distance from the inlet, increasing first, reaching a maximum, and then decreasing with increasing axial distance and that the axial position of the maximum enhancement increases with CNT concentration and Reynolds number Re. These results differ from those of Paritosh et al. [6] who found that the enhancement of heat transfer increases with the axial distance under laminar regime. Mayer et al. [7] have investigated experimentally the effect of axial distance on convective heat transfer of aqueous multi-walled carbon nanotubes flowing through a straight horizontal tube. They showed that at low axial distance, the use of MWCNT-water nanofluid enhances slightly the convective heat transfer; nevertheless, at high axial distance, the addition of MWCNT penalizes the heat transfer.

Evaluating the literature shows that the results are very dispersed. In fact, some works have confirmed that the addition of CNTs can enhance significantly the thermal performances $[8,9]$, 
while other works have found the opposite: the addition of nanoparticles may cause significant pressure losses that result in a negative energy balance [10]. Wang et al. [11] have studied the heat transfer and pressure drop under laminar flow for CNT based nanofluids with volumetric concentration of $0.05 \%$ and $0.24 \%$. They showed that the nanofluids at low concentration $(0.05 \%)$ increase the heat transfer with small extra penalty in pressure drop and have a great potential for applications in the heat transfer. The effect of MWCNT functionalization on laminar convective heat transfer of water-based nanofluids was reported in [12]. The authors also evidenced convective heat transfer enhancement with increasing the nanofluid content and Reynolds number.

In the continuity of our previous researches [13], this paper focuses on thermophysical properties measurement and heat transfer performance of carbon nanotubes nanofluids, stabilized by lignin as surfactant, considering both water and water-EG mixture as base fluid. Also, the effect of low concentration in CNT is considered. Based on our investigations, this work aims to select the appropriate composition of CNT nanofluids for heat transfer applications.

\section{Materials and experiments}

Here, MWCNT produced by Nanocyl with an average aspect ratio of 160 (average length: $1.5 \mu \mathrm{m}$; average diameter: $9.2 \mathrm{~nm}$ ) were dispersed by the two-step method in water and a mixture of water and ethylene-glycol (50:50 in mass\%). As reported by the manufacturer, density and carbon purity of MWCNTs' were respectively $1800 \mathrm{~kg} \mathrm{~m}^{-3}$ and $90 \%$. Lignin, known as byproduct of paper industry, was used as surfactant to ensure nanoparticles dispersion and avoid nanoparticles agglomeration and sedimentation [14]. The surfactant was purchased from Sigma Aldrich, with product number 471003. Low nanoparticle content of 0.01 and 0.05 in mass\% (respectively 0.0277 and 0.0055 in vol.\%) was here considered in a trade-off between thermal conductivity enhancement and viscosity penalty. These nanofluids were obtained from the dilution of initial suspension with $1 \%$ in mass fraction of nanotubes from mechanical mixing. A constant surfactant/CNTweight ratio of 2 was also maintained with dilution.

Due to the lack of reliable models for the prediction of thermal conductivity and viscosity of CNT nanofluids [15,16] and the influence of surfactant on these properties [17], they were measured with experimental setups previously used $[15,16]$ for an operating temperature of $45^{\circ} \mathrm{C}$. 
As explained thereafter, this is the average temperature between inlet and outlet in the inner tube of the coaxial heat exchanger presently used.

Thermal conductivity of both nanofluids and base fluids were measured using a KD2 Pro thermal Property analyser (Decagon Devices Inc.) based on transient hot wire method with an accuracy of $\pm 3.5 \%$ [15]. The rheological properties were measured under steady-state condition with a Kinexus Pro rheometer (Malvern Inst.) equipped with a cone and plate geometry of $60 \mathrm{~mm}$ in diameter and $1^{\circ}$ in angle, with well controlled temperature of $\pm 0.01^{\circ} \mathrm{C}$ and with a maximum deviation of $4 \%$. The comprehensive description of rheological measurements and validation as well with calibration fluids were reported in a previous paper [16].

As shown also in previous works [18], density and heat capacity of CNT based nanofluids can be evaluated respectively from the following well-known formulas [20,21].

$$
\begin{gathered}
\rho_{n f}=\phi \rho_{n p}+(1-\phi) \rho_{b f} \\
C_{p, n f}=\frac{\phi\left(\rho C_{p}\right)_{n p}+(1-\phi)\left(\rho C_{p}\right)_{b f}}{\phi \rho_{n p}+(1-\phi) \rho_{b f}}
\end{gathered}
$$

\section{Coaxial heat exchanger}

The home-made coaxial heat exchanger was previously described in [13]. The main features are recalled as follows and described in figure 1.

- The experimental setup consists of a test section of a stainless steel coaxial heat exchanger with entrance with inner tube length of $660 \mathrm{~mm}$, inner diameter of $18.7 \mathrm{~mm}$ and a thickness of $1.3 \mathrm{~mm}$ and an annular tube diameter of $47.6 \mathrm{~mm}$ and thickness of $1.7 \mathrm{~mm}$.

- An adiabatic section of $200 \mathrm{~mm}$ was left outside the test section to ensure fully developed flow through the inner tube, allowing the measurement to be made after the hydrodynamic and thermal entry and ensuring that the axial variations of temperatures are mainly related to heat transfer and not to the hydrodynamic flow.

- Four platinum probes are positioned at the inlet and outlet of test section for measuring the respective working fluid temperatures.

- To evaluate the wall temperature distribution of the inner, $8 \mathrm{~K}$-type thermocouples with an accuracy of $0.1{ }^{\circ} \mathrm{C}$ after calibration, were inserted at axial positions of 5(T1), 20(T2), 30 (T3), 60(T4), 140(T5), 185(T6), 245(T7) and $385 \mathrm{~mm}$ (T8) from the inlet. 
- The pressure drops of the inner tube were measured using piezo-resistive pressure transmitters (Rosemount) over a range of 0-5 bar with an accuracy of $0.075 \%$. All the data were recorded by a data acquisition system (Labview). The entire test section was insulated with polyurethane foam, as shown in Figure 1.a, in order to minimize the heat losses.

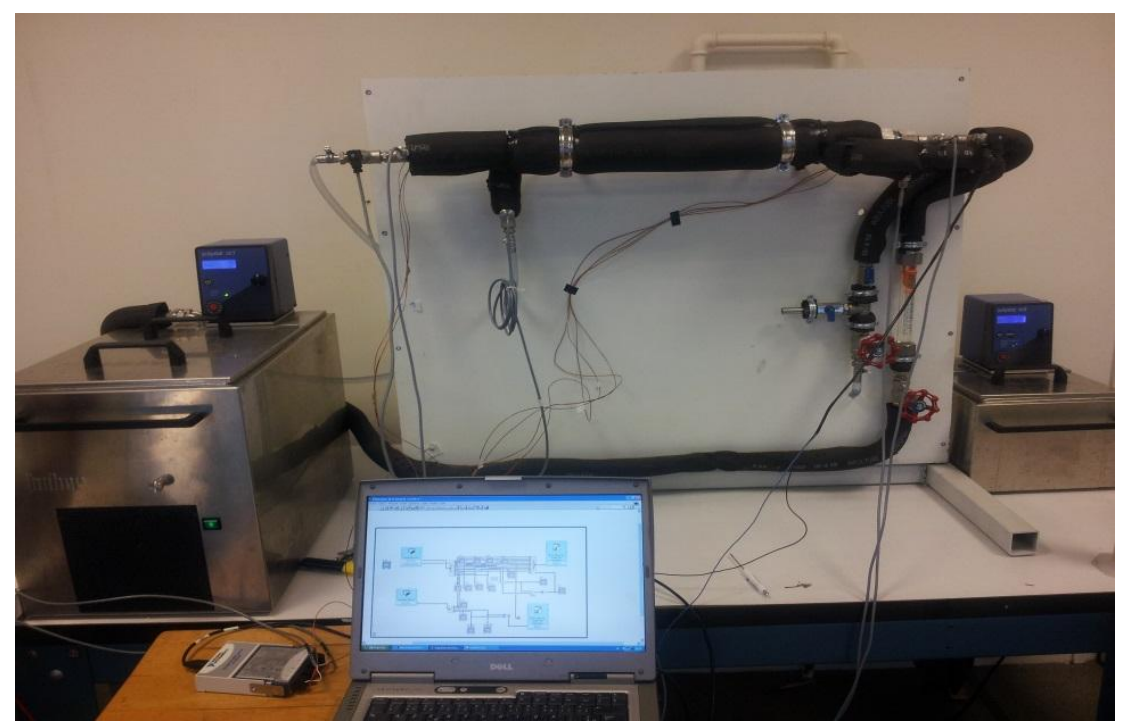

a

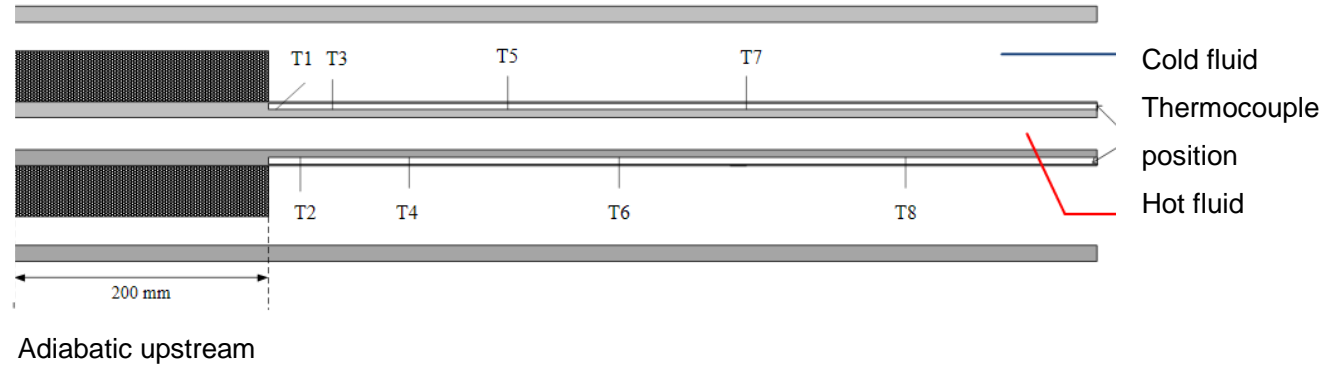

b

Figure 1a. Experimental set-up for heat exchange measurement; b.Schematic view of coaxial heat exchanger

The measurements are made for a co-current flow maintaining the hot fluid inlet temperature at $50^{\circ} \mathrm{C}$ and the inlet temperature of cold fluid at $10^{\circ} \mathrm{C}$. The water flow rate in the annular tube was maintained constant and equals to $5.6 \mathrm{l} / \mathrm{min}$ for all tests. The flow rate in the inner tube varied between 0.31 and $3 \mathrm{l} / \mathrm{min}$. For the tested flow rates, the maximum temperature difference between the inlet and the outlet of the annular tube does not exceed $1{ }^{\circ} \mathrm{C}$. For this reason, the heat transfer properties were considered to be evaluated from fixed wall temperature boundary condition. 
As mentioned in our previous work [13], the nanofluid flow rate was measured directly from the time required to accumulate a fixed volume of the nanofluid using a 3-way valve. This 3-way valve was also used for flow system cleaning between runs even with the same nanofluid. For each volumetric flow rate, the data acquisition is performed when a steady state is reached. This was achieved when the difference between inlet and outlet temperature of both inner and annular tubes becomes constant. For all flow rates, the average temperature of the operating temperature in the inner tube is about $45{ }^{\circ} \mathrm{C}$. This enables to avoid possible instability of nanofluids and surfactant efficiency with regards to temperature.

The thermocouples inserted at the heat exchange surface, as shown in figure 1.b, measure the temperatures of the inner surface and the outer surface of the central tube. To determine the temperature distribution at the inner surface of the central tube, a corrective term was considered to take into account the conductive effect between the grooves where the thermocouples are positioned and the internal surface of the central tube.

For each axial position $\mathrm{x}$, the axial heat density is calculated as follows:

$$
q(x)=\frac{T_{t h}(x)-T_{a}}{\lambda_{t h}} e_{1}
$$

Where $\mathrm{T}_{\mathrm{th}}(\mathrm{x})$ is the axial temperature displayed by the thermocouple and $\mathrm{T}_{\mathrm{a}}$ is the temperature of the annular tube.

$\lambda_{\text {th }}$ is the average thermal conductivity of the thermocouples and $e_{1}$ is the thickness of the groove $(\mathrm{m})$.

The axial heat density can also be expressed as a function of the axial temperature of the inner surface of the central tube, and reduces to equation (4) at first approximation due to low thickness of tube.

$$
q(x)=\frac{T_{p}(x)-T_{t h}(x)}{\lambda_{s}} e_{2}
$$

Where $\lambda_{\mathrm{s}}$ is the average thermal conductivity of the central tube (stainless steel); $\mathrm{e}_{2}$ is the thickness between the thermocouple and the tube inner surface.

The local convective heat transfer coefficient was obtained according to the following equation: 


$$
h_{c h}(x)=\frac{q_{c h}}{\left(T_{c h}(x)-T_{p}(x)\right)}
$$

$\mathrm{T}_{\mathrm{ch}}(\mathrm{x})$ is the fluid local temperature in the inner tube. It was determined as follows [19]:

$$
T_{c h}(x)=T_{p}(x)+\left(T_{c h, e}-T_{p}(x)\right) \exp \left(-\frac{P x}{\left(\dot{m} C_{p}\right)_{c h}} \bar{h}\right)
$$

$\mathrm{P}$ is the perimeter of the inner tube; $\bar{h}$ is the average convective heat exchange coefficient.

The local Nusselt number was calculated using equation (7):

$$
N u(x)=\frac{h(x) D_{h}}{\lambda_{c h}}
$$

The accuracy of the platinum probes and $\mathrm{K}$-thermocouples used is about $0.1{ }^{\circ} \mathrm{C}$ after calibration. In the heating circuit, the flow rate was calculated by measuring the time required to accumulate a fixed volume. This operation was repeated five times for each flow rate to minimize measurement uncertainties. The maximum relative error is also estimated to $2 \%$.

The maximum heat flux uncertainty can be evaluated based on [22] as following:

$$
\frac{\delta q}{q}=\left[\left(\frac{\delta \dot{m}}{\dot{m}}\right)^{2}+\left(\frac{\delta C_{p}}{C_{p}}\right)^{2}+\left(\frac{\delta \Delta T}{\Delta T}\right)^{2}\right]^{\frac{1}{2}}
$$

Hence, the uncertainty of heat flux and convective heat exchange were evaluated to 4.5 and $7.45 \%$, respectively.

Before studying the nanofluids, the coaxial heat exchanger was tested and calibrated with distilled water. The validation procedure and results of global parameters are previously presented and detailed in [13].

Figure 2 shows the evolution of local Nusselt number of distilled water (W) in inner tube with the axial distance for three different Reynolds numbers 600, 950 and 1850. For low axial distances (less than $0.25 \mathrm{~m}$ ), we note that Nusselt number decreases with axial distance and then stabilizes for values greater than $0.25 \mathrm{~m}$.

We can observe that for $\mathrm{Re}=600$, the Nusselt value achieved at high axial distances is about 3.66, which corresponds to a thermally developed regime. All the values closely agree with theoretical and expected ones with distilled water. 


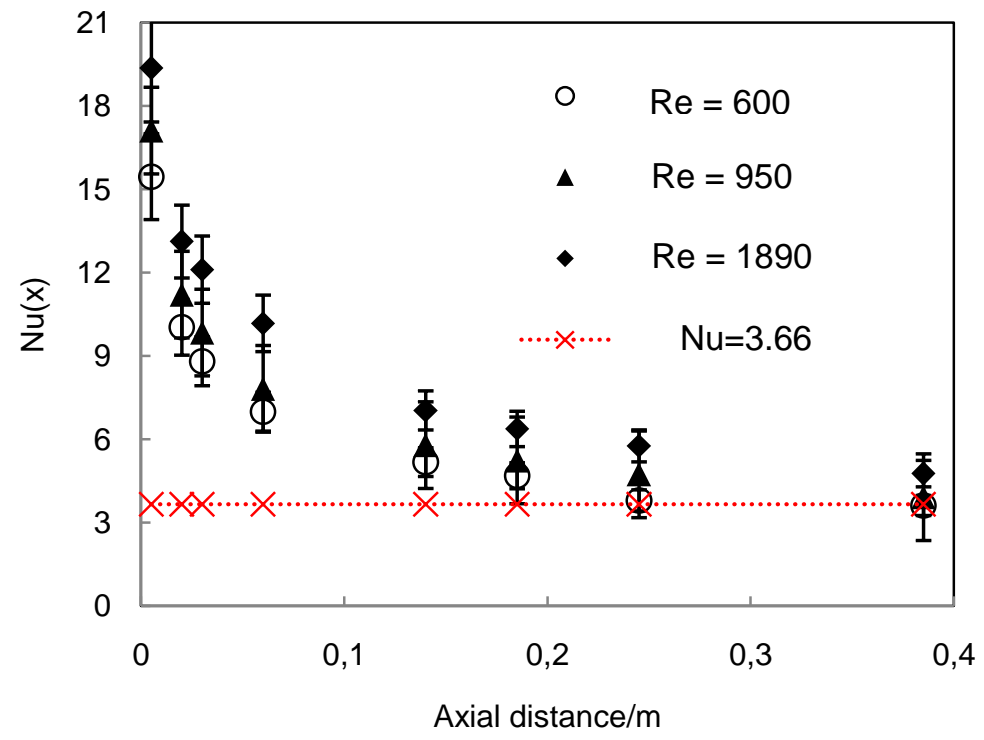

Figure 2Local Nusselt number versus axial distance of W/W configuration in function of axial position and Reynolds number

\section{Experimental results}

In the following main figures, water-based nanofluids are denoted N2, and nanofluids containing EG are noted N6.The thermophysical properties of nanofluids investigated for an operating temperature of $45^{\circ} \mathrm{C}$ are reported in table 1 . It is observed that density and heat capacity of nanofluids respectively increase and decrease with volume fraction, and depend on the nature of the base fluid. When EG is present within the base fluid, density and specific heat are naturally higher, respectively lower than with water only. Thermal conductivity enhancement also increases with volume fraction of nanofluids, the enhancement being greater with $\mathrm{EG}+\mathrm{W}$ based fluid. Rheological behavior of nanofluids with $0.05 \%$ in mass is reported on figure 3 . It is found that water-based nanofluids are shear-thinning for shear rate lower than 200s-1, then a Newtonian region is observed. Shear-thinning effect is absent with EG+W as base fluid. In the Newtonian region, the viscosity values increase slightly with volume fraction in comparison with viscosity of base fluids, and, as expected, are higher with the presence of EG. Similar trends were observed with nanofluids of lower mass concentration of $0.01 \%$, viscosity value in the Newtonian region being lower than with $0.05 \%$ in mass.

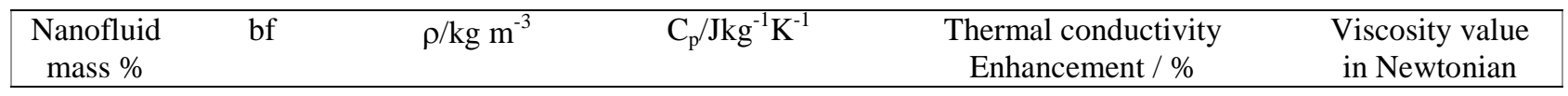




\begin{tabular}{|cccccc|}
\hline & & & & & $\begin{array}{c}\text { region } \\
/ \mathrm{mPa} \text { s }\end{array}$ \\
\hline 0.01 & $\mathrm{~W}$ & 990.25 & 4179.7 & 10.9 & 0.604 \\
0.01 & $\mathrm{EG}+\mathrm{W}$ & 1038.84 & 3368.6 & 13.2 & 2.18 \\
0.05 & $\mathrm{~W}$ & 990.44 & 4178.2 & 11.3 & 0.632 \\
0.05 & EG+W & 1039.01 & 3367.6 & 15.4 & 2.35 \\
\hline
\end{tabular}

Table 1 Thermophysical properties of CNT nanofluids

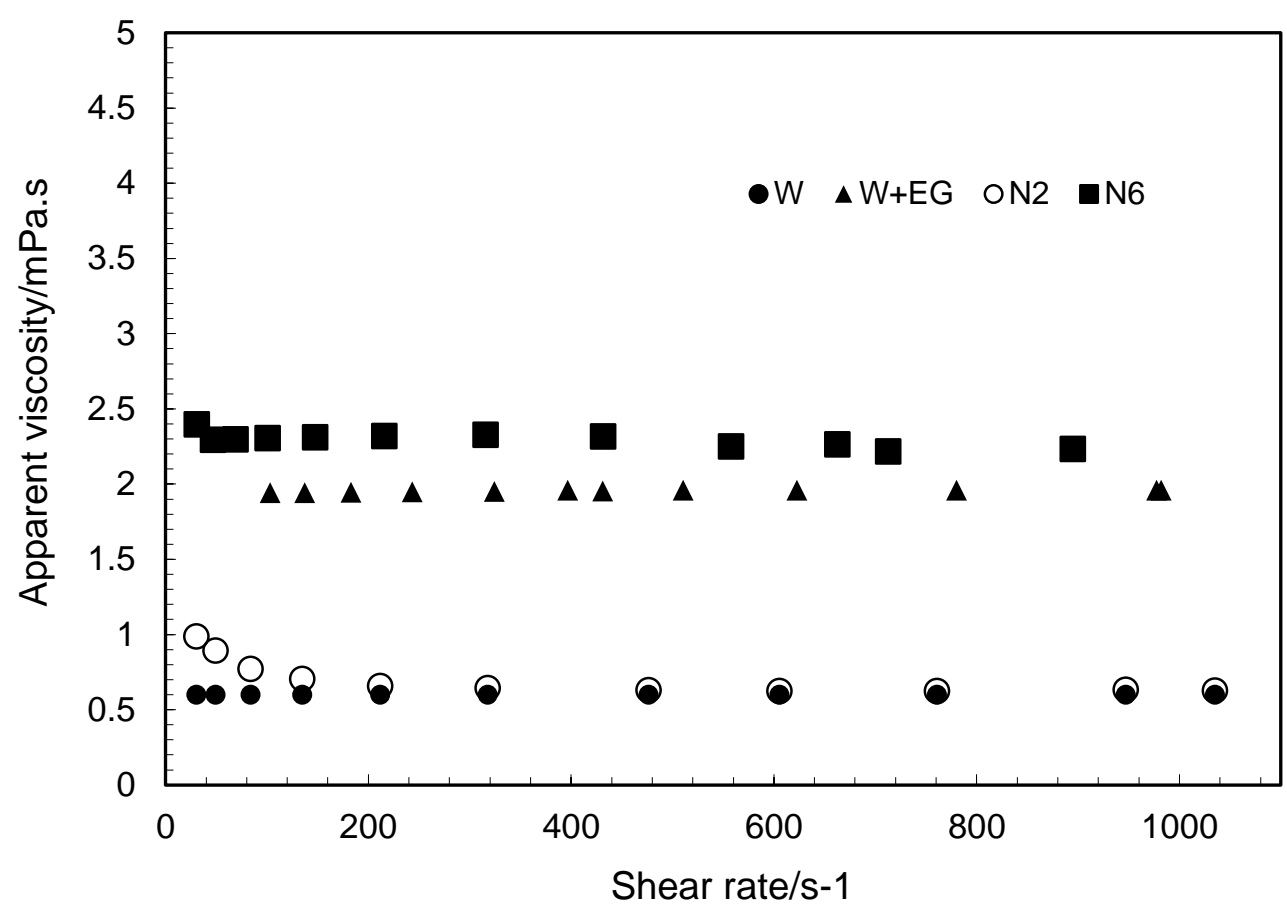

Figure 3 Viscosity of base fluids and nanofluids with $0.05 \%$ in wt. at $45^{\circ} \mathrm{C}$

Wall temperature distribution of nanofluids along tube axial distance is shown in figure 4 for $\mathrm{Re}=600$ and both tested weight fraction. It was observed that for both nanofluids, temperature decreases significantly with axial distance at the entrance region. However, for axial distance higher than $0.25 \mathrm{~m}$, the influence of the axial distance on the wall temperature becomes negligible. This implies that heat transfer within the heat exchanger occurs mainly at the entrance region. The temperature along the axis is slightly higher with water as base fluid in comparison with EG+water, and higher than water only. Similar tendencies were also reported for higher Re numbers. It is also found that temperature difference reduces when Re number is increased. The 
main difference in changing volume fraction was observed with water as base fluid as it was found that temperature is higher with the highest nanoparticle weight fraction.



(a)



(b) 
Figure $4 \mathrm{Wall}$ temperature distribution along the tube axial distance for $\mathrm{Re}=600$ and wt. $\%$ of 0.01 (a) and 0.05

The effect of base fluid and nanoparticle content on local relative convective heat transfer is reported on figure 5 for Re number of 950 . For both nanofluids, convective heat transfer increases slightly with axial distance and depends on both base fluid and weight fraction in nanoparticles. Higher the weight fractionbetter heat transfer enhancement is. In addition, better enhancement is also obtained with the mixture of $\mathrm{EG}+\mathrm{W}$ as base fluid. This agrees well with previous studies [23]. The maximum enhancement is about 18.5\% for N6 with 0.05 in mass\%, while it is around $11.8 \%$ with $\mathrm{N} 2$ for the same concentration. This trend is similar for all $\mathrm{Re}$ number, without significant effect when Re is changed within the range presently investigated from 600 to 1890 .

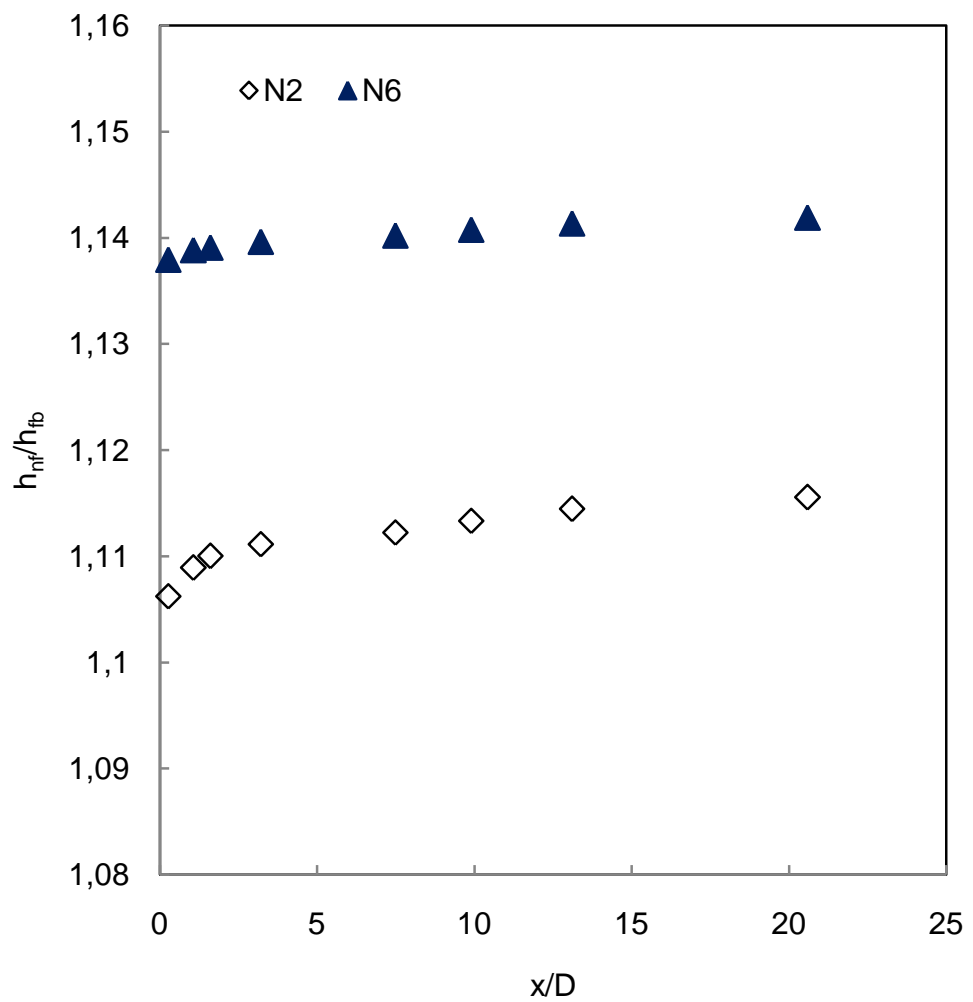

(a) 




(b)

Figure 5 Local relativeconvective heat transfer along the tube axial distance for $\mathrm{Re}=950$ and wt. $\%$ of 0.01 (a) and $0.05(b)$

\section{Conclusion}

Thermophysical properties and heat transfer performance under laminar regime of carbon nanotubes nanofluids at an operating temperature of $45^{\circ} \mathrm{C}$, stabilized by lignin as surfactant, considering both water and water-EG mixture as base fluid were investigated. Effect of nanoparticle content was also considered.

Accordingly, the following conclusions can be drawn:while viscosity and density are increased with the presence of EG, nanofluid with EG+W as base fluid and higher nanoparticle content appears as the best candidate for heat transfer applications. Actually, both thermal conductivity and convective heat transfer coefficient along the tube is higher in comparison with other compositions.

\section{References}

[1] Thollander P, Palm J. Improving Energy Efficiency in Industrial Energy Systems, SpringerVerlag London; 2013. 
[2] Tao WQ, He YL, Wang QW, Qu ZG, Song FQ. A unified analysis on enhancing single phase convective heat transfer with field synergy principle. Int J Heat Mass Transfer. 2002;45:48714879.

[3] Huminic G, Huminic A. Application of nanofluids in heat exchangers: a review. Renew.Sust. Energy Rev.2012;16:5625-5638.

[4] Halelfadl S, Adham AM, Mohd-Ghazali N, Maré T, Estellé P, Ahmad R. Optimization of thermal performances and pressure drop of rectangular microchannel heat sink using aqueous carbon nanotubes based nanofluid. App.Thermal Eng.2014;62:492-499.

[5] Ding Y, Alias H, Wen D,Williams RA. Heat transfer of aqueous suspensions of carbon nanotubes (CNT nanofluids). Int J Heat Mass Transfer. 2006;49:240-250.

[6] Paritosh G, Jorge LA, Marsh C, Carlson TA, Kessler DA. An experimental study on the effect of ultrasonication on viscosity and heat transfer performance of multi-wall carbon nanotubebased aqueous nanofluids. Int J Heat Mass Transfer. 2009;52:5090-5101.

[7] Meyer JP, Mc Krell TJ, Grote K. The influence of multi-walled carbon nanotubes on singlephase heat transfer and pressure drop characteristics in the transitional flow regime of smooth tubes. Int J Heat Mass Transfer. 2013;58:597-609.

[8] Wang XQ, Mujumdar AS. A review on nanofluids - Part II: Experiments and applications. Brazilian J Chem Eng. 2008;25:631-648.

[9] Karami M, Bahabadi MA, Delfani S, Ghozatloo A. A new application of carbon nanotubes nanofluid as working fluid of low-temperature direct absorption solar collector. Solar Energy Mat Solar Cells. 2014;212:114-118.

[10] Piratheepan M, Anderson TN. An experimental investigation of turbulent forced convection heat transfer by a multi-walled carbon-nanotubes nanofluid, Int. Com. Heat Mass Transfer. 2014;57:286-290.

[11] Wang J, Zhu J, Zhang X, Chen Y. Heat transfer and pressure drop of nanofluids containing carbon nanotubes in laminar flows. Exp Thermal Fluid Sci.2013;44:716-721.

[12] Ebrahim Hosseinipour E, Heris SZ, Shanbedi M. Experimental investigation of pressure drop and heat transfer performance of amino acid-functionalized MWCNT in the circular tube. $\mathbf{J}$ Therm Anal Calorim. 2016;124:205-214. 
[13] Halelfadl S, Estellé P, Maré T. Heat transfer properties of aqueous carbon nanotubes nanofluids in coaxial heat exchanger under laminar regime, Exp Thermal Fluid Sci. 2014;55:174180.

[14] Estellé P, Halelfadl S, Maré T. Lignin as dispersant for water-based carbon nanotube nanofluids: Impact on viscosity and thermal conductivity. IntCom Heat Mass Transfer. 2014;57:8-12.

[15] Estellé P, Halelfadl S, Maré T. Thermal conductivity of CNT water based nanofluids: Experimental trends and models overview, JThermal Eng.2015;1:381-390.

[16] Halelfadl S, Estellé P, Aladag B, Doner N, Maré T. Viscosity of carbon nanotubes waterbased nanofluids: Influence of concentration and temperature. Int J Thermal Sci. 2013;71:111117.

[17] Shanbedi M, Heris ZS, Maskooki A. Experimental investigation of stability and thermophysical properties of carbon nanotubes suspension in the presence of different surfactants. J Therm Anal Calorim. 2015;120:1193-1201.

[18] Halelfadl S, Maré T, Estellé P. Efficiency of carbon nanotubes water based nanofluids as coolants.Exp Thermal Fluid Sci. 2014;53:104-110.

[19] Pak BC, Cho YI. Hydrodynamic and heat transfer study of dispersed fluids with sub-micron metallic particles. Exp.Heat Transfer. 1998;11:151-170.

[20] O'Hanley H, Buangiorno J, McKrell T, Hu LW. Measurement and model validation of nanofluid specific heat capacity with Differential Scanning Calorimetry. Adv Mech Eng 2012;181079.

[21] Incorpera FP, Bergman TL, Lavine AS, Dewitt DP. Fundamentals of Heat and Mass Transfer. 7th Edition, John, John Wiley and Sons; 2011.

[22] Moffat R.J. Describing the uncertainties in experimental results. Exp Thermal Fluid Sci. 1988;1:3-17.

[23] Phillip J, Shima PD. Thermal properties of nanofluids, Adv CollInterface Sci. 2012;183184:30-45. 